Artigo

\title{
Etnomatemática, jogos de linguagem e movimentos de contraconduta de mulheres no ocupar o Quadrado
}

\author{
Ethnomathematics, language games and women's counter-conduct \\ movements when occupying the Quadrado
}

\section{Etnomatemáticas, juegos de lenguaje y movimientos de contraconducta de mujeres al ocupar el Quadrado}

\author{
Letiane Oliveira da Fonseca ${ }^{1}$ \\ [0000-0002-6410-9895] \\ Márcia Souza da Fonseca ${ }^{2}$ \\ [0000-0001-9215-4370]
}

\begin{abstract}
Resumo
O presente artigo é recorte de uma dissertação de mestrado que objetivou identificar e analisar os jogos de linguagem produzidos por um grupo de mulheres moradoras do Quadrado, comunidade localizada no bairro Porto da cidade de Pelotas/Rio Grande do Sul, quando narram as suas vivências durante a ocupação. Os aportes teóricos utilizam teorizações pós-estruturalistas, tendo por referência estudos na perspectiva etnomatemática de Knijnik, Wanderer, Giongo e Duarte (2013), nos jogos de linguagem de Wittgenstein (2000) e no conceito de contraconduta de Michel Foucault (2008). A investigação foi desenvolvida em uma abordagem qualitativa de caráter exploratório e, para a coleta de dados, de inspiração etnográfica, com instrumentos de observação participante, diário de campo e fotografias. Para compor a produção dos dados utilizou-se entrevistas narrativas, quando quatro moradoras, de gerações diferentes, relatam as suas vivências sobre a ocupação. O material coletado foi analisado de forma descritiva-analítica conforme as ideias de Paraíso (2012), considerando, como ferramentas analíticas, a noção de contraconduta de Foucault (2008) e de jogos de linguagem, usos, semelhanças de família e formas de vida de Wittgenstein (2000). Neste trabalho discutimos as narrativas das mulheres sobre formas de ocupar o local. As análises apontam que os jogos de linguagem das mulheres são provenientes de práticas por elas vivenciadas à medida que foram se estabelecendo no lugar; suas lutas, resistências e movimentos de contraconduta. Evidenciamos a existência de outras formas de matematizar; mensurar, associar, classificar, indicar tempo, presentes no processo de ocupar o Quadrado.
\end{abstract}

Palavras-chave: Etnomatemática. Jogos de linguagem. Contraconduta. Educação Matemática.

\begin{abstract}
The present article is part of a Master's dissertation which aimed at identifying and analyzing language games produced by a group of women living in the Quadrado neighborhood, a community located in the Porto borough in the city Pelotas/Rio Grande do Sul, when they tell about their experiences during the occupancy. The theoretical contributions use post-structuralist theorizations, having as reference studies in the ethnomathematics perspective of Knijnik, Wanderer, Giongo and Duarte (2013), in the language games of Wittgenstein (2000) and in the concept of counter-conduct of Michel Foucault (2008). The investigation was carried out in a qualitative approach of exploratory feature and, for data collection, of ethnographic inspiration, with instruments of participating observation, field diary and

${ }^{1}$ letianefonseca@yahoo.com.br, Mestre em Educação Matemática, Professora, Secretaria Municipal de Educação, Pelotas/RS/Brasil.

2mszfonseca@gmail.com, Doutora em Educação, Professora, Universidade Federal de Pelotas, Pelotas/RS/Brasil.
\end{abstract}


pictures. In order to arrange the production of data we used narrative interviews, when four residents, of different generations, report their experiences concerning the occupancy. The material collected was analyzed in a descriptive-analytical way according to the ideas of Paraíso (2012), considering, as analytical tools, the idea of counter-conduct of Foucault (2008) and of language games, uses, similarities of family and ways of life of Wittgenstein (2000). In the present work we discussed the narratives of women on ways to occupy the place. The analysis point out that the women's language games arise from your practices; their fights, resistances and counter-conduct movements. We highlight the existence of other forms to mathematize, measure, associate, classify, indicate time, present in the process of occupying Quadrado. We highlight the existence of other forms of measuring, associating, classifying, indicating time, present in the process of occupying Quadrado.

Keywords: Ethnomathematics. Language games. Counter-conduct. Mathematical Education.

\section{Resumen}

El presente artículo es el recorte de una disertación de máster que tenía como objetivo identificar y analizar los juegos de lenguaje producidos por un grupo de mujeres residentes del Quadrado, una comunidad en el barrio de Porto en la ciudad de Pelotas/Rio Grande del Sur (Brasil), cuando cuentan sus vivencias durante su ocupación. La aportación teórica utiliza teorizaciones posestructuralistas, teniendo como referencia estudios con perspectiva de las etnomatemáticas de Knijnik, Wanderer, Giongo y Duarte (2013), los juegos de lenguaje de Wittgenstein (2000) y el concepto de contraconducta de Michel Foucault (2008). La investigación se desarrolló con un abordaje cualitativa de carácter exploratorio y, para la recogida de datos, de inspiración etnográfica, con instrumentos de observación participante, diario de campo y fotografías. Para componer la producción de datos se han utilizado entrevistas narrativas, cuando cuatro residentes, de distintas generaciones, cuentan sus vivencias sobre la ocupación del Quadrado. El material recogido fue analizado de manera descriptiva-analítica acorde a las ideas de Paraíso (2012), considerando como herramientas analíticas la idea de contraconducta Foucault (2008) y de juegos de lenguaje, usos y similitudes de familias y formas de vida de Wittgenstein (2000). En este trabajo se discuten las narrativas de las mujeres sobre maneras de ocupar el local. Los análisis indican que los juegos de lenguaje de las mujeres provienen de sus prácticas; sus luchas, resistencias y movimientos de contraconducta. Se evidencia la existencia de otras maneras de matematizar; mensurar, asociar, clasificar e indicar tiempo, presentes en el proceso de ocupar el Quadrado.

Palabras claves: Etnomatemáticas. Juegos de Lenguaje. Contraconduta. Educación Matemática

\section{Introdução}

O presente artigo é recorte de uma dissertação de mestrado que objetivou identificar e analisar os jogos de linguagem produzidos por um grupo de mulheres moradoras do Quadrado, comunidade localizada no bairro Porto da cidade de Pelotas, Rio Grande do Sul, quando narram as suas vivências durante a ocupação. A pesquisa analisou os processos de ocupação, construção e habitação do local.

Neste recorte buscamos identificar e analisar os jogos de linguagem produzidos pelo grupo de mulheres quando narram as suas vivências durante o processo de ocupar o local.

Para isso, foram utilizadas, leituras relacionadas à perspectiva Etnomatemática de Knijnik, Wanderer, Giongo e Duarte (2013), um grupo que se propôs a olhar a Etnomatemática como um movimento vinculado a seus deslocamentos e a suas continuidades, enfatizando que a "Etnomatemática segue interessada em discutir a política de conhecimento dominante praticada na escola" (KNIJNIK et al., 2013, p. 13), apresentando "[...] suas conexões com as 
novas configurações econômicas, sociais, culturais e políticas do mundo de hoje" (KNIJNIK et al., 2013, p.14), sobre o conhecimento hegemônico que é difundido nas escolas e as novas perspectivas para a Educação Matemática.

Com isso, adotou-se, três pilares norteadores: a Etnomatemática, os jogos de linguagem e a contraconduta. A primeira relacionada à perspectiva teórica baseada nas leituras de Knijnik et al. (2013); a segunda, refere-se à fase de maturidade do filósofo Wittgenstein (2000); e a última, aos estudos de Michel Foucault, com o objetivo de estabelecer, assim, um entrelaçamento com os estudos da Etnomatemática e dos jogos de linguagem em práticas sociais fora da escola.

A seguir descreveremos as ferramentas teóricas que auxiliaram a análise, o lugar e sujeitos da pesquisa, seguido da metodologia adotada e, por fim, atracamos no Quadrado para atentar aos jogos de linguagem das mulheres quando ocupam o local.

\section{Algumas teorizações}

\subsection{A Etnomatemática e os Jogos de Linguagem}

A Etnomatemática, na perspectiva aqui adotada, se interessa por suspeitar dos discursos hegemonicamente contados como ciência, propondo uma mudança de perspectiva que "[...] possibilitasse a desnaturalização da matemática na qual fomos socializados." (KNIJNIK, 2010, p. 23), permitindo um olhar para a Matemática produzida nas práticas populares. Isso possibilita o resgate de saberes silenciados, adentrando outros jogos de linguagem, como os praticados por grupos de profissionais, por mulheres e homens para atender as suas necessidades de sobrevivência, entre outros.

As reflexões adotadas neste estudo articulam os jogos de linguagem à Etnomatemática, colocando-as em um movimento que reconhece outras racionalidades Matemáticas que não são socialmente legitimadas. Apoiando-se nos estudos de jogos de linguagem de Wittgenstein, Knijnik et al. (2013), destacam que,

[...] o pensamento de Wittgenstein, em nosso entendimento, é produtivo para nos fazer pensar em diferentes Matemáticas (geradas por diferentes formas de vida - como associadas a grupos de crianças, jovens, adultos, trabalhadores de setores específicos, acadêmicos, estudantes, etc.), que ganham sentido em seus usos (KNIJNIK et al., 2013, p.30, grifos do autor).

Nesse sentido, optou-se, investigar um grupo de mulheres que compartilham o mesmo local de moradia e todas as lutas que envolvem estabilização, ocupação e organização no local com os jogos de linguagem provenientes de sua forma de vida, pensando que "[...] representar uma linguagem significa representar-se uma forma de vida" (WITTGENSTEIN, 2000, p. 32). Desse modo, representar outras maneiras de matematizar, assumindo a não universalização da Matemática dita científica.

O pensamento produzido pelo senso comum diz que a padronização ou universalização de conceitos matemáticos no mundo foi criada para facilitar o entendimento ou a comunicação entre os povos. Essa padronização esconde preceitos que não pretende-se discutir neste artigo, mas realça a importância em ter pesquisas que destaquem outros jeitos de conhecer, calcular, e de saber, outras racionalidades Matemáticas, além do que está sendo difundido no currículo escolar. 
[...] a Etnomatemática questiona também a noção de que a Matemática Acadêmica expressaria "o conjunto de conhecimentos acumulados pela humanidade", apontando que em tal processo há a legitimação de uma forma muito específica de produzir Matemática: aquela vinculada ao pensamento urbano, heterossexual, ocidental, branco e masculino. É justamente esse suposto "consenso" perante o que conta como "conhecimento acumulado pela humanidade" que a Etnomatemática problematiza, destacando aquelas formas de dar significado aos saberes matemáticos, os quais diferem, muitas vezes do modo hegemônico (KNIJNIK, et al., 2013, p. 27).

Pode-se dar significado aos saberes matemáticos tratando a respeito da Matemática Acadêmica, Matemática Escolar e outros usos matemáticos. Sendo assim, é possível perceber conforme Knijnik et al., (2013), que a Matemática Acadêmica e a Escolar não são as únicas Matemáticas, e que "[...] a linguagem da Matemática Acadêmica está marcada por mecanismos de exclusão que se fazem presentes desde a sua constituição como campo de conhecimento" (KNIJNIK, et al., 2013, p. 25).

Essa constituição na ciência foi tornando-a como uma Matemática única excluindo a existência de outros usos matemáticos, porém estudos na perspectiva etnomatemática mostram a existência de outros jogos de linguagem matemáticos. Aqui a Matemática Acadêmica é vista como prática de um conhecimento científico articulado pelos matemáticos, já a Matemática Escolar provém da Acadêmica e refere-se a uma Matemática exercida no ambiente escolar composta por um conjunto de conteúdos que atende a disciplina de Matemática e ao corpo de membros escolares (alunos, professores, entre outros), além de outros usos matemáticos que são produzidos por saberes fora do âmbito escolar, em diferentes formas de vida.

Uma forma de reconhecer esses saberes produzidos fora do âmbito escolar é olhar ao redor do Quadrado e analisar os jogos de linguagem de mulheres, moradoras desse local.

Para tanto, nos alinhamos à obra de maturidade de Wittgenstein, que segundo Condé (1998) detém-se na indagação "Como a linguagem funciona?", com o viés de explicá-la em contexto de uma forma de vida.

Considera-se essa pergunta como ponte para o estudo realizado neste trabalho, pois conhecer os jogos de linguagem de uma comunidade, um grupo, neste caso, presente no contexto de vida das mulheres, visibiliza compreender como a linguagem funciona naquele local, naquele grupo específico, jogos de linguagem presentes das suas narrativas sobre a comunidade em que vivem.

E o que seriam esses jogos de linguagem? Condé (1998) explica que seriam diversos usos que a linguagem possui, sendo diversas linguagens, dando origem à expressão jogos de linguagem, ou seja, uma palavra dependendo do contexto em que está inserida, terá uma significação naquela forma de vida na qual se tem um determinado jogo de palavras, tendo funcionamento em seu uso.

Wittgenstein (2000) exemplifica explicando que se um professor aponta para um objeto e diz a um aluno ser uma pedra - denominando-a com o uso da linguagem de ser uma pedra -, o aluno repete a palavra que o professor falou, isso decorre de um processo semelhante de linguagem, um jogo adotado por ambos naquele contexto, no qual denominam o objeto com o nome de pedra, dando a sua significação mediante o contexto que estão inseridos. 
Podemos também imaginar que todo o processo do uso das palavras (...) é um daqueles jogos por meio dos quais as crianças aprendem sua língua materna. Chamarei de "Jogos de linguagem", e falarei muitas vezes de uma linguagem primitiva como de um jogo de linguagem. E poder-se-iam chamar também de jogos de linguagem os processos de denominação das pedras e da repetição da palavra pronunciada. Pense os vários usos das palavras ao se brincar de roda. Chamarei também de 'jogos de linguagem 'o conjunto da linguagem e das atividades com as quais está interligada (WITTGENSTEIN, 2000, p.30, grifos do autor).

Um jogo de linguagem é uma criação de um determinado grupo específico, cada grupo possui suas regras. Moreno (1995), mostra que a linguagem adotada na concepção de Wittgenstein é utilizada também para "exprimir pensamentos sobre objetos que podem ser descritos empiricamente" (MORENO, 1995, p. 63), como indicar a cor de um objeto, sendo utilizada ainda "quanto sobre objetos dos quais nada pode ser dito" (MORENO, 1995, p. 64), como exemplo as sensações humanas. Isso mostra a amplitude dos diversos usos que uma linguagem pode gerar no contexto ao qual pertence, no jogo que a rege.

As ações que vão construindo a linguagem decorrem de uma criação, "A descrição conduz, todavia, a uma modificação de nosso pensamento: passamos a compreender com melhor clareza os usos que nós próprios fazemos da linguagem" (MORENO,1995, p.71), com isso, a linguagem faz parte da forma de vida em que ela está sendo descrita.

Conhecer os jogos de linguagem produzidos por um determinado grupo, depende de compreender qual é o jogo em que está inserido e quais as semelhanças de família existentes entre diferentes jogos. Condé (1998) explica o termo "semelhanças de família", utilizado na obra de Wittgenstein, enfatizando que sua relação se constitui pelas formas de vida, que essa perspectiva abandona uma posição semântica para introduzir uma pragmática, ou seja, as palavras só terão sentindo no contexto em que estão inseridas, podendo ter semelhanças de família com outras palavras, mas sempre levando em consideração a forma de vida em que a linguagem está inserida.

Condé (1998) enfatiza que, nas Investigações Filosóficas, a significação de uma palavra se deve mediante o uso que dela é feito, em diferentes contextos, e salienta também que as semelhanças de família apresentam variações dentro de um determinado jogo de linguagem, podendo aparecer ou desaparecer na passagem de um jogo para outro, mostrando que a forma de vida envolve não apenas uma dimensão biológica, mas também uma dimensão cultural.

Essas semelhanças de família são aproximações de uma linguagem para outra, como se tivessem um parentesco em comum. Por exemplo, a própria palavra jogo traz essas semelhanças, pois, quando pensa-se em jogo, infere-se que é um conjunto de regras, através das quais cada jogo terá suas regras diferentes, no entanto possuem algo em comum, ou seja, semelhanças, já que um jogo utilizando uma bola pode ser jogado em diversos locais, e qual seria a semelhança de família de um jogo para o outro? Neste caso, seria o uso comum de um objeto denominado de bola.

Relacionar o pensamento filosófico presente nas Investigações, com o uso da linguagem em diferentes formas de vida, faz refletir sobre a investigação dos jogos de linguagem produzidos por diferentes grupos. Com isso, entende-se que a linguagem é proveniente de uma forma de vida e possui seus usos e significados mediante o contexto que está inserido determinado grupo. 
Ao observar o grupo de mulheres do Quadrado, nos seus jogos de linguagem, pode-se analisar os significados que cada jogo apresenta. Condé (1998) propõe que "Nas 'Investigações' Wittgenstein nos mostra que não é partindo do mundo que construímos a linguagem, mas contrariamente, é a linguagem que constrói o mundo" (CONDÉ, 1998, p. 140).

\subsection{A Contraconduta}

Investigar as narrativas de mulheres sobre a ocupação de um local envolve reflexões não somente de questões locais, mas também de contexto histórico, social, e político e de um contexto de resistência. A noção de contraconduta se fez necessária nesta investigação no sentido de mostrar a maneira como as mulheres se conduziam durante a ocupação do Quadrado.

Nesse contexto social, foi necessário direcionar um olhar para as lentes teóricas de Foucault (2008), em especial a seu curso "Segurança, território, população", ministrado entre 1977-1978, visto que, em meio às ideias desenvolvidas pelo filósofo durante o curso, foi possível destacar o conceito de contraconduta.

Para melhor compreender o conceito, é necessário percorrer alguns caminhos com destaques da obra do autor quando analisa os mecanismos que regulam a população. Para empreender tal análise ele remete ao conceito de biopoder, "[...] o conjunto dos mecanismos pelos quais aquilo que, na espécie humana, constitui suas características biológicas fundamentais vai poder entrar numa política, numa estratégia política, numa estratégia geral de poder" (FOUCAULT, 2008, p. 3). Evidencia que o poder está relacionado às características de vida do ser humano e provém de um conjunto de procedimentos para o controle da população.

No sentido de controle da população, destaca-se a análise do autor sobre "[...] o papel de mostrar quais são os efeitos de saber que são produzidos nessa sociedade pelas lutas, os choques, os combates que nela se desenrolam, pelas táticas de poder que são elementos dessa luta" (FOUCAULT, 2008, p.5). Ademais, para compreender o meio no qual a sociedade é produzida com seus impactos, lutas e resistência, vale mencionar a noção de segurança como "[...] uma certa maneira de acrescentar, de fazer funcionar, além dos mecanismos propriamente de segurança, as velhas estruturas da lei e da disciplina" (FOUCAULT, 2008, p. 14).

Cabe destacar, também, que a segurança torna-se um mecanismo de controle social. Dessa maneira, é pertinente sublinhar a fala de Foucault (2008) de que a soberania se exerce no território, a disciplina sobre o corpo dos indivíduos e a segurança sobre a população.

A governamentalidade é uma forma de poder que é exercido sobre a população, que vai modificando a vida na sociedade, utilizando-se de táticas, mecanismos do governo para fins do próprio poder. Para Rago (2016), esse conceito foi cunhado por Foucault a partir da união das palavras governo com mentalidade, sendo o governo responsável por conduzir a conduta do outro, a partir do poder pastoral. Para o filósofo, a governamentalidade é um mecanismo, proveniente da tecnologia pastoral, vindo do cristianismo que alcançou o Estado. Como analogia, o pastor conduz o seu rebanho e, o Estado, conduz a população.

O pastorado se configura, de fato, com o cristianismo sendo um mecanismo de poder durante séculos, todavia o poder pastoral e o político mantiveram suas características. Nos diz o filósofo, "Como quer que seja, através de todos os sentidos, há algo que aparece claramente: nunca se governa um Estado, nunca se governa um território, nunca se governa uma política. Quem é governado são as pessoas" (FOUCAULT, 2008, p.165). 
Foucault (2008) menciona um exemplo de objeto de governo, utilizando como metáfora o governo da condução de um navio. Nota-se que o capitão não governa os marujos, mas, sim, o navio, porém os marujos estão dentro do navio e logo são conduzidos. Ele adota essa mesma reflexão ao governo de uma cidade que tem seus indivíduos, os quais vão sendo subjetivados, realçando, assim, a ideia de um governo das pessoas.

[...] de fato, a atividade que consiste em conduzir, a condução, se vocês quiserem, mas é também a maneira como uma pessoa se conduz, a maneira como se deixa conduzir, a maneira como é conduzida e como, afinal de contas, ela se comporta sob o efeito de uma conduta que seria ato de conduta ou de condução (FOUCAULT, 2008, p.25).

No âmbito de resistências ao poder pastoral, a crise do pastorado, o filósofo destaca as revoltas de conduta como resistências a esse poder, "[...] revoltas específicas de conduta, aqui também deixando à palavra "conduta" toda a sua ambiguidade" (FOUCALT, 2008, p. 256), enfatizando que são movimentos que demonstram insatisfação e acabam por requerer outra condução diferente, mas que ao mesmo tempo não querem ser mais conduzidos, seria um ato libertador, um conduzir-se. Cita como exemplo a revolta da mulher sobre o seu estatuto "[...] essas revoltas de conduta estão muitas vezes ligadas a esse problema das mulheres, do seu estatuto na sociedade, na sociedade civil ou na religiosa. Essas revoltas de conduta floresceram nos conventos femininos [...]" (FOUCAULT, 2008, p.259). Podemos pensar que muitas conquistas das mulheres foi proveniente de revoltas no sentido de não deixá-las serem conduzidas.

Para Foucault (2008), as resistências de conduta não são autônomas, dependem de fatores como "Por quem aceitamos ser conduzidos? Como queremos ser conduzidos? Em direção ao que queremos ser conduzidos?" (FOUCAULT, 2008, p. 260). O governo começou a exercer o poder pastoral conduzindo a conduta da população gerando revoltas em âmbito político e não tanto religioso. $O$ autor dá destaque para conflitos sobre o fazer guerra, cujo recrutamento gerava resistências, "[...] ser soldado foi uma conduta, uma conduta política, uma conduta moral [...]" (FOUCAULT, 2008, p. 261), mas nem todos querem ou servem para serem soldados, mesmo que exista um recrutamento ou uma seleção não voluntária já estipulada pelo Estado independente de querer ser conduzido ou não.

Foucault nomeia essas resistências, revoltas de conduta, como contraconduta, "contraconduta no sentido de luta contra os procedimentos postos em prática para conduzir os outros" (ibid., 2008, p. 266). Ele menciona alguns exemplos de contracondutas pastorais da Idade Média, o ascetismo; as comunidades que criticam o poder pastoral contra o batismo, eucaristia; a mística e experiências contra esse poder; o retorno da escritura sem a presença de mediador pastoral, sem alguém que interprete; a crença que dispensa os pastores visto que Cristo voltará. Por fim, o autor expõe que esses exemplos de contraconduta ao poder pastoral foram o aporte para a governamentalidade que também tem suas contracondutas, tais como movimentos de revolta urbana, camponesa, etc.

[...] as práticas de dominação cruzam todas as instâncias da vida social e implicam movimentos de resistência e contraconduta. Esses dois movimentos - de resistência e contraconduta -, por serem mobilizados em relações de governança e poder, têm a convicção da população sobre a importância de ter, sob seu domínio, alguns atores no cotidiano. Entre esses 
atores, temos, por exemplo, os loucos, os desempregados, os criminosos, os delinquentes, os pobres, os anormais (VEIGA-NETO; LOPES, 2011, p.111).

A partir do exposto acima é possível pensar que o processo de ocupação do espaço do Quadrado ocorreu por conta das lutas das mulheres para se manterem no local. Embora sem infraestrutura, sem água, sem energia elétrica e com um lugar propício a alagamentos, elas foram conduzindo as suas vidas por meio de práticas de sobrevivência, governando a si mesmas.

Conforme Costa (2019), as atitudes e lutas frente às práticas de governo modernas possuem seu rastro nas contracondutas, afirma que "é a partir da abordagem das contracondutas que Foucault pode problematizar questões políticas" (COSTA, 2019, p. 62).

Conforme exposto, a perspectiva etnomatemática, os jogos de linguagem e movimentos de contraconduta norteiam essa investigação; os jogos de linguagem dão subsídios para mostrar os usos matemáticos existentes na forma de vida das mulheres e a noção de contraconduta contribui para uma reflexão política e social sobre o processo de ocupação do local.

\section{Caminhos investigativos}

O lugar da investigação é uma pequena comunidade localizada no bairro Porto da cidade de Pelotas, antigamente conhecida por "Vila das Doquinhas", habitada por pescadores que foram constituindo suas moradias ao redor do Cais, na área portuária da cidade. Foi intitulado pela comunidade de moradores e pessoas que frequentam a região. Não se trata de um quadrado conforme a Matemática Escolar como visto na geometria, e sim um ambiente que possui um formato mais próximo a um trapézio.

O espaço antigamente servia como atracadouro ao Porto de Pelotas e sua localização fica às margens do Canal São Gonçalo, sendo conhecido, também, como, Cais do Porto, Doca Fluvial, Doquinhas e Cais do Quadrado.

Há relatos de que os moradores foram se estabelecendo devido à grande oferta de empregos que existia nas proximidades da zona portuária, e por ser um lugar sem moradias, desabitado, composto por banhado e planta espadana ${ }^{3}$.

O local hoje é composto por muito residências; as próximas ao cais, em sua maioria, de alvenaria, e uma outra área, separada por um dique de contenção a alagamentos, onde predominam casas de madeira construídas com uma certa altura para evitar que, em períodos de alagamento, a água entre nas residências. As ruas não possuem calçamento, somente uma delas possui um fino asfalto esburacado e uma travessa, alguns paralelepípedos desgastados.

Hoje o Cais se tornou um espaço de lazer com moradias ao seu redor. Nas áreas de expansão ocupadas, ocorre o predomínio de pouca estrutura de saneamento e um aglomerado de casas.

Nesse cenário de investigação foram convidadas a participar da pesquisa quatro mulheres moradoras de três áreas de ocupação, nas seguintes localizações: área inicial (Wilma, 85 anos); área intermediária (Ana Maria, 50 anos); área lateral (Gilda Maria, 63 anos); e, área nova (Ladi Cristine, 35 anos). Tais áreas são subdivisões realizadas para esclarecer o contexto de ocupações das moradias e dos lugares que foram habitados no decorrer dos anos.

\footnotetext{
${ }^{3}$ Nome popular atribuído a uma planta de nome científico Typha domingensis, também chamada de taboa.
} 
Entender como se procedeu a organização dessas mulheres, seu papel, suas resistências, conflitos, suas histórias de ocupação, pode-se tornar algo precioso não só no campo da Educação Matemática em geral mas, particularmente, no âmbito da Etnomatemática. Optou-se por pesquisar somente narrativas de mulheres para verificar e expor sua representatividade no local, ampliando seu espaço de visibilidade na sociedade durante o processo de ocupação.

Para investigação elegeu-se a abordagem qualitativa, para compreender o grupo de mulheres na sua forma de vida. Foi uma pesquisa de caráter exploratório e para a coleta de dados, baseou-se no método de inspiração etnográfica. Esse método permite uma interação com foco no processo desenvolvido, valorizando a experiência do grupo pesquisado.

A inspiração etnográfica foi realizada com o objetivo de conhecer o Quadrado, permitindo fazer a pesquisa de campo e aproximações com as participantes através de uma imersão no campo, observando atentamente, durante o tempo de pesquisa, detalhes sobre o lugar e suas modificações, a rotina das mulheres dentro do Quadrado, além de encontros para coletar suas narrativas.

O contato constante no campo comportou a realização de um estudo detalhado, possibilitando a flexibilidade e criatividade na investigação, permitindo uma observação participante para melhor explorar o objeto (comunidade-sujeitos) e suas perspectivas sobre as experiências vividas.

As observações foram realizadas em todas as etapas da pesquisa, em que cada detalhe foi escrito no diário de campo sobre o ambiente onde moram as mulheres, suas casas, calçamento das ruas, ou não, atividades laborais desse grupo, atividades realizadas no local, dentre outras.

As entrevistas foram desenvolvidas com base na perspectiva pós-estruturalista, valorizando as histórias de vida, a linguagem, experiências, emoções, memórias, o que compõe a verdade daqueles sujeitos.

As narrativas das mulheres produziram discursos, esses emergiram de seus jogos de linguagem, mostrando as formas como foram e são subjetivadas.

A subjetividade é, portanto, processo de produção: o eu está, em constante transformação, e o homem se constitui pela ação das circunstâncias, pelo encontro com a alteridade, pela forma como ele vivencia as experiências na relação com o outro (IBRAHIM; VILHENA, 2014 p.122).

Elas dizem certas coisas, de uma certa forma, falam o que falam, e porque falam. Isso tem a ver com suas vivências com suas formas de vida. As narrativas, obra das entrevistas, e os demais materiais coletados foram analisados, considerando como ferramenta analítica o conceito de contraconduta, nos estudos de Foucault (2008) e conceitos de jogos de linguagem, usos, semelhanças de família e formas de vida de Wittgenstein em sua obra de maturidade.

A articulação entre esses dois teóricos e as leituras na perspectiva etnomatemática adotada permitem identificar e analisar os jogos de linguagem produzidos pelas mulheres quando narram as suas vivências durante a ocupação. Importante neste estudo é o conceito de discurso, definido por Foucault (2008a, p. 55) como "práticas que formam sistematicamente os objetos de que falam". As narrativas das mulheres constituem a história de ocupação do local e nesse processo destaca-se as suas práticas discursivas, pois dão vida e estão implicadas na produção das suas identidades. Práticas discursivas entendidas como 
[...] um conjunto de regras anônimas, históricas, sempre determinadas no tempo e no espaço, que definiram, em uma dada época e para uma determinada área social, econômica, geográfica ou linguística, as condições de exercício da função enunciativa (FOUCAULT, 2008a, p. 133).

Considerando que o discurso produz as coisas que são faladas, esse ato das fala das mulheres é a produção de seu modo de vida, das maneiras de significar o seu mundo, suas práticas discursivas e suas histórias, sua constituição. Pois,

Estamos falando do sujeito que afeta e é afetado pelo seu meio, o sujeito que se modifica e que se reinventa a cada contingência de seu processo histórico, o sujeito constituído nas e pelas práticas sociais, situado e contextualizado culturalmente, agindo por razões e intenções, e não por causas. Estamos nos referindo à visão antropológica de sujeito, da qual compartilhamos (IBRAHIM; VILHENA, 2014 p.121).

Partindo das teorizações pós-estruturalistas, iniciou-se o processo de análise dos materiais coletados, de acordo com Meyer e Paraíso (2012), com procedimentos ou estratégias descritivo-analíticas. Realizou-se leitura minuciosa investigando nas narrativas os jogos de linguagem utilizados pelas mulheres nas práticas de suas vivências, identificando, descrevendo e analisando esses jogos. Os materiais foram organizados em grupos que emergiram após o processo descritivo-analítico e seus títulos são algumas frases retiradas das narrativas das moradoras que, por serem pronunciadas diversas vezes, mereceram destaque para introduzir a análise. Ocupar: era tudo um banhado; Construir: a gente aumentou; Habitar: hoje é um ponto turístico. Para este estudo analisaremos o processo de Ocupar.

\section{Atracadouro - Ocupar: era tudo um banhado}

O Quadrado foi um local construído por seus moradores, um lugar não habitado, constituído de espadana e banhado. Sua ocupação não foi realizada de maneira rápida, houve um processo de luta e organização; luta no sentido de buscar junto à prefeitura da cidade melhores condições de infraestrutura e saneamento básico. Já a organização, ocorreu por meio de estratégias utilizadas para se manterem no local.

[...] A gente teve que aterrar para fazer um chalezinho em cima, um chalezinho, aquele chalezinho era quarto, era cozinha, tudo era uma coisa só, porque não tinha condições na época né, não tinha água, não tinha luz, não tinha nada, era o banhado. E foi aterrar até com cinzas que saia do engenho, saia cinza e eles despejavam o caminhão para gente arrumar [...] (Wilma).

Wilma relatou sobre o início de sua instalação há mais de 50 anos. Nasceu e criou-se em outro bairro e, com o passar do tempo, por não ter condições de pagar aluguel, buscou as Doquinhas (Quadrado). Wilma destaca que havia poucas pessoas no início da ocupação,

[...] era só meia dúzia de casas, não tinha muita gente, não tinha nada de casa era um mato, era só o tempo da mamona ${ }^{4}$, aquelas árvores de mamona e taboa do banhado por causa do banhado que tinha no fundo [...] (Wilma).

\footnotetext{
${ }^{4}$ Mamona é uma planta originária da Ásia meridional. No Brasil, pode ser conhecida como mamoneira, rícino, carrapateira, bafureira, baga e palma-criste.
} 
A moradora utiliza a palavra "meia dúzia" para exemplificar a pouca quantidade de moradores existentes no período de ocupação do local, não que exatamente expresse essa quantidade. Além disso, utilizou a expressão "era só o tempo da mamona", atribuindo a um período em que prevalecia no ambiente do Quadrado mais aquelas plantas do que as pessoas.

Destaca também a espessura da atual rua onde reside, referindo-se a ela no diminutivo "[...] aqui era uma estradinha que tinha a mamona, aquelas árvores que davam carrapicho, $o$ que tinha bastante aqui era mamona e aqueles carrapicho que pegavam na roupa da gente" (Wilma). É interessante notar como a imagem tratada na fala de Wilma se remete à planta existente no local.

Analisou-se o uso frequente da palavra mamona que apresenta jogos de linguagem atribuído na forma de vida da moradora para representar o período passado, contrariando a imagem de uma verdade única sobre uma palavra ou conceito, mostrando a possibilidade de outros usos. A partir disso, vale lembrar que "Wittgenstein não analisa experiências possíveis, mas sim formas possíveis de expressões linguísticas, isto é, usos possíveis de palavras" (MORENO, 1995, p.115), liberando o pensamento de imagens fixas que vão sendo construídas pela linguagem, nesse caso o uso da palavra mamona é associado a imagens vivenciadas na época.

Os espaços do Quadrado foram ocupados a partir do aterramento de áreas de banhado para posterior apropriação dos terrenos. "Na época a pessoa chegava botava a casa em cima do terreno [...] e marcava com arame na volta, só não era nada medido, tudo foi assim, a pessoa chegava fazia a casinha estava vazio o terreno [...]" (Wilma). A narrativa mostra que não era necessário ter uma precisão da demarcação do espaço, pois o mais relevante naquela forma de vida, era ter o seu terreno, e ter um lugar onde morar. Contudo, condições, como crescimento populacional e convivência social, trouxeram à tona a necessidade de organização para a própria sobrevivência, com isso as mulheres foram criando seu modo de medir.

Ana Maria foi morar com sua família pois havia sido retirada do Gasômetro, outra ocupação próxima ao Quadrado, nomeado, assim, devido às ocupações serem do lado da usina de energia. A moradora mencionou que pelo fato da construção de um engenho, os moradores foram retirados e deslocaram-se à procura de um outro terreno, indo morar nas Doquinhas. Porém, após um tempo, foram avisados que deveriam sair do local,

[...] o dono da indústria Olvebra queria que o pessoal saísse porque eles produziam ali muito trigo e muita casca de arroz e fazia muita poeirama, e ai disseram que iam tirar todo o pessoal dali por causa que a Olvebra ia ampliar, foi na época que levaram todo mundo para o Pestano (Ana Maria).

Ana Maria, sua família e outros moradores do Quadrado foram viver em outro, no qual a prefeitura disponibilizou um espaço para morarem, porém, segundo a moradora, a família de Wilma permaneceu. Mas o pai de Ana Maria, ao ver que depois de um tempo ainda havia moradores, retornou ao Quadrado, todavia já tinha perdido o seu terreno, o qual havia aterrado "[...] o local que era do meu pai aí já não estava mais aí, outra pessoa já tinha pego. Aí o meu pai pegou o local aqui na frente do Quadrado que era a Alberto Rosa primeira travessa porque ele perdeu o ponto dele na realidade" (Ana Maria).

Pode-se notar que a resistência de alguns moradores foi fundamental para a ocupação oficial do ambiente, a fala da moradora evidencia esse fato "A Olvebra até tentou tirar, o pessoal voltava, aí foi que eles desistiram e deixaram o pessoal morando no mesmo ponto 
porque não adianta o pessoal não queria sair daqui porque já tinha saído muita gente do gasômetro" (Ana Maria). Verificou-se que o jogos de linguagem atribuído por Ana Maria em, perdeu o seu "ponto", esse "ponto", evidencia uma racionalidade de indicar o local em que moravam, sendo a palavra 'ponto' referente ao espaço.

Essas formas de resistência no ato de voltar para o local e permanecer nele configuram os primeiros passos desse jogo de poder, e pode-se estabelecer o ato inicial de um movimento de contraconduta dos moradores, como alega Costa (2019, p. 68) "A contraconduta designa, portanto, o movimento nos jogos de poder capaz de criar outras possibilidades de ação, na medida em que recusa, não propriamente o governo, mas o modo como se é governado". Nesse sentido, as mulheres não só resistiram, mas mostraram que as Doquinhas era o lugar onde iam permanecer.

A moradora enfatiza também o que encontrou no local em sua chegada,

[...] era tudo um banhado só, aí a gente veio aterrou cada um foi aterrando a sua parte pegando seu pedaço e construindo as suas casas porque antes era tudo banhado não tinha nem a rua aqui, que vai para o Quadrado pela Bento Martins, para passar era tudo banhado, o povo que foi abrindo ruas e construindo suas próprias casas [...] (Ana Maria).

Neste caso, o movimento de contraconduta pode ser visto pela estratégia utilizada em "abrir rua", como mencionam Veiga-Neto e Lopes (2011a, p. 62) "[...] as contracondutas permitem emergir novas formas de condução ou outros rumos para a história das populações", assim ao se referir a perspectiva narrada pelas mulheres ao se conduzirem abrindo ruas, acabaram alterando o cenário local, adequando-o às suas necessidades, conduzindo-se.

Na mesma trajetória, temos Gilda Maria e Ladi Cristine, moradoras de uma geração mais recente. Gilda Maria, morava no Rio de Janeiro e menciona que "[...] o pai dos meus filhos foi embora e o outro morreu, e eu fui me embora para cá para o Rio Grande do Sul, para Pelotas e estou criando eles". Gilda conheceu uma pessoa e foi morar no Quadrado com ela. Relata que,

[...] aí quando eu vim para cá, aqui era tudo banhado, era tudo, tudo banhado, eram poucas casas aqui, o resto tudo era banhado. [...] aí vim morar eu, e mais os meus quatros filhos. Daqui assim para a frente, era uma pecinha pequenininha e o resto tudo isso aqui que tu pode ver era banhado [...] Era uma ruazinha bem estreitinha, e esse dique, esse aterro aí era mais alto $e$ tinha de fora a fora, era arame de espinho, e aí tinha um pessoal no náutico gaúcho que fazia remo (Gilda Maria).

Nesse mesmo viés de ocupar, tem-se Ladi Cristine que narra, [...] era só campo, [...] aí eu comprei e aí peguei vim morar aqui mas era tudo posse, não tinha casa, não tinha nada, era só um estilo um galpão de chão batido, aí aos poucos eu entrei, e aos poucos fui construindo."

Ladi Cristine explica que quando foi morar no local solicitou apoio da prefeitura da cidade e informou que o local era considerado baixo e enchia de água,

Como aqui era muito baixo e enchia de água, não tinha como colocar o chalé, aí foi onde eles fizeram uma entrevista né que eles iam ver a medida do terreno, que eles davam pela prefeitura o chalé pré-fabricado duas peças, me deram duas caçambas de aterro, aí o aterro sim eu tive que aterrar para depois eles vim e montar o chalé, deu no espaço todo foram duas caçambas (Ladi Cristine). 


\section{Contou também que,}

[...] eu comprei um terreninho, era tipo uma pecinha só né não tinha nem banheiro, aí eu comprei ali e fiquei uns 8 meses morando naquela casinha e como era muito pequena e o terreno também aí provisoriamente eu peguei e fiquei ali (Ladi Cristine).

Semelhante ao jogo de linguagem de Wilma, Gilda Maria e Ladi Cristine, Ana Maria narra sobre a sua casa [...] a minha primeira casinha foi um chalezinho só, uma pecinha só".

Nas narrativas do grupo de moradoras percebeu-se o uso de um jogo de linguagem predominante de um mesmo significado proveniente do início de suas moradias com palavras no diminutivo "chalezinho", "estradinha", "casinha" "terreninho", "pecinha", "ruazinha", "estreitinha", pequenininha" e das frases "uma coisa só" e "não tinha nada", "pecinha só", remetendo à ideia de uma linguagem para expressar a relação de pouca quantidade com relação às condições financeiras existentes naquele período.

Wittgenstein (2000, p. 27) propõe que "[...] as palavras da linguagem denominam objetos-frases são ligações de tais denominações - [...] cada palavra tem uma significação. Esta significação é agregada a palavra. É o objeto que a palavra substitui". Cada palavra utilizada nessa narrativa associa-se a sua significação que tem como o objeto o ambiente de moradia associado à situação financeira.

Para representar, na forma de vida das mulheres, a situação em que viviam é possível estabelecer uma semelhança de família, na qual o objeto comum seria o ato da comparação. Na condição social em que vivem, ao estabelecerem que as coisas são pequenas por estarem imersas no ambiente de poucas condições financeiras, elas mostram seus usos matemáticos para relacionar a quantidade de coisas que possuem naquele momento.

Desta maneira, a racionalidade que opera os jogos de linguagem das mulheres é própria daquele grupo, não podendo generalizar, e a comparação se realiza devido à associação - imagem - de relacionar a pouca condição financeira daquele período a palavras no sentido diminutivo. Knijnik (2017, p. 50) nos diz que "[...] os significados que damos às palavras são mediados por regras que são concebidas em nossas práticas sociais".

No intuito de explorar mais sobre o local, destacou-se as narrativas acerca da inexistência de instalação hidráulica e elétrica, onde as mulheres utilizaram estratégias para se manterem no local. Wilma salienta que,

[...] a água veio muito depois, nós carregava a água lá da outra quadra né, aí depois com o tempo botaram uma torneira de água na esquina que o pessoal ia tirar, primeiro eu carregava de balde depois botei uma mangueira lá que vinha aqui em casa. [...] quando a gente veio pra cá não tinha luz não tinha nada, ah nem sei quantos anos faz que tenho luz aqui, na década de 70 , fiquei muito tempo sem água e sem luz.

Já Ana Maria contou que,

Aí a gente enchia carregava, [...] se eu fosse pegar um latão de água, os meus irmão iam junto para ajudar. Aí as vezes para as pessoas não passar muito trabalho tipo meu pai já dizia: leva dois latão três latão né, que é para não ter que tá indo toda hora para a bica, porque tinha muita fila de gente para pegar água.

As atitudes das mulheres retratam o que afirma Costa (2019, p. 68) "Possibilidade do sujeito conduzir-se a si mesmo em meio a condução exercida por outros", pois não tinham acesso rápido à água e, com isso, as ações das mulheres podem ser caracterizadas como uma 
estratégia de condução de sua conduta frente aos mecanismos de poder, mecanismos vinculados ao fato de não haver instalação de água justamente porque não era para ter moradias naquele ambiente.

Ana Maria relatou que tinha que buscar água pela manhã, tarde e noite, e isso foi durante um longo período mas,

Depois conforme começou a juntar casas, porque na realidade eram muito poucas casas aqui então não dava para formar ainda uma vila né, então a prefeitura não se interessava, aí depois sim começou a lotear, começou a encher de gente, aí foi ficando tudo ocupado de casas, aí foi quando começou a aparecer vereadores, os candidatos no bairro para saber quem tinha água quem não tinha água, que era para fazer as instalações de água, depois que ficou tudo preenchido de casas, aí foi quando eles começaram a fazer instalações de água (Ana Maria).

À medida que a prefeitura percebeu que já existia um número maior de casas, precisou olhar para o local e resolveu instalar água e energia elétrica. Pensando em um mecanismo que controle a população, como reflete Foucault (2008), em sua genealogia, é pertinente analisar esse fato pela governamentalidade, visto que o governo, neste caso, a cidade, e os envolvidos nesse jogo de poder perceberam que poderiam conduzir essas pessoas, pois já existia mais casas, assim sendo, resolveram fornecer as devidas instalações para as moradias. Esse olhar vincula-se a um mecanismo de segurança, no qual é possível regular essas instalações, sendo uma forma inicial de controlar os sujeitos.

É notável que, para melhorias de condições de vida de uma cidade, bairro e ocupações, é necessário ter essas instalações básicas, mas o que impera, nessa análise, é mostrar as lutas mediante as vivências desse grupo para terem o que é chamado hoje de Quadrado, pois nem sempre foi assim. Ouvir, transcrever e descrever as narrativas dessas mulheres não foi algo fácil, mas ao mesmo tempo foi como construir uma linha do tempo no pensamento da pesquisadora que, ao olhar em cada quadra do lugar, fez a reflexão sobre as transformações do local até os dias de hoje. Neste sentido, ainda hoje, é perceptível muita falta de estrutura, pois as mesmas mulheres e os moradores em geral não possuem rede de esgoto, assim permanece a existência de valetas nos fundos das residências desembocando no canal São Gonçalo.

Dando sequência a essa linha temporal, é relatado a maneira como as roupas eram lavadas naquele período,

[...] a gente lavava as roupas tudo nos carreiros o pessoal todo botava a trouxa na cabeça ia lá para os carreiros lavar roupa [...] era tipo assim que nem a gente vê essas novelas antigas hoje e a gente bah a gente passou pelo aquilo ali, que a novela tipo graças a Deus a gente não era mais escravo naquela época, mas era como se fosse a escravatura, né, porque aí botava a trouxa de roupa na cabeça, aí dali as pessoas enxaguavam a roupa no arroio mesmo torciam e traziam para casa para botar para secar era tudo lavado na água do arroio na beira do arroio (Ana Maria).

Carreiros $^{5}$ são rampas compostas por pilares, local onde as roupas eram lavadas conforme narrado por Ana Maria. Essas rampas ficam próximas ao Canal São Gonçalo e localizam-se no contorno do Cais no lado oposto às residências do Quadrado. Na fala da moradora, nota-se uma comparação de sua vivência com relação ao que é exposto na mídia através de novelas. Conforme Fischer (2001, p. 212) "a mídia ao mesmo tempo que é um lugar

\footnotetext{
${ }^{5}$ Nome atribuído pelas moradoras às rampas que prendiam os navios.
} 
de onde várias instituições e sujeitos falam - como veículo de divulgação e circulação dos discursos considerados "verdadeiros" em nossa sociedade -, também se impõe como criadora de um discurso próprio".

Nesse sentido, é notável a persuasão que a mídia representa frente aos sujeitos, ao passo que atribuem semelhanças em suas práticas, pois o ato de carregar trouxas de roupas na cabeça não necessariamente se remete ao tempo da escravidão, muitas pessoas carregam na cabeça para distribuição do peso das roupas, contudo a imagem que se forma no pensamento da moradora remete a isso, e denota o quanto o discurso midiático subjetiva sujeitos.

Ainda sobre a lavagem das roupas, tem-se a maneira como eram estendidas, como narra a moradora eram colocadas no arame farpado. "Pegava por parte, aí na frente da minha casa é aqui essa parte do arame farpado era minha, a casa da vizinha era ali a frente da casa da vizinha era a parte dela, cada um usava o seu espaço da frente de sua casa" (Ana Maria). Ao indicar o local onde as roupas ficavam, informou também que, naquela época, a pobreza era tanta que usavam o próprio arame - a farpa - para prender as roupas, pois não tinham prendedor, inferindo que mesmo sem tê-los as roupas não caiam.

$\mathrm{Na}$ trajetória a respeito da instalação de água, tem-se a narrativa de Ladi Cristine que diz "[...] a instalação de água até tem né? Mas não é regularizada porque como eles dizem que aqui é área e risco e posse até mesmo por causa da beira d'agua então eles não dão, não regularizam". Essa moradora mora na área nova do Quadrado, é uma parte que fica às margens do canal São Gonçalo e foi ocupada por uma maior quantidade de pessoas depois de um tempo.

Essa área é dividida por um dique de contenção de água e como a moradora menciona, uma área de risco pois é a parte que alaga constantemente, visto que a bomba de drenagem de água se localiza em cima do dique, drenando a água referente ao lado oposto a sua moradia, que beneficia a população onde se encontram as outras três participantes da pesquisa.

Sobre a iluminação, à época, destaca Ana Maria,

[...] iluminação não tinha, a gente usava lampião, quem não tinha condições, tinha que comprar querosene todos os dias né, aí quando não tinha condições de comprar querosene todos os dias aí a gente usava candeeiro [...] depois aí já passava fio de luz por essa rua começaram a botar postes essas coisa assim, aí depois começaram a botar poste aí cada um foi ligando sua luz.

As moradoras criaram estratégias utilizando outros instrumentos para obter água e energia elétrica, o ato de morar em um local não propício à moradia, segundo elas, ocorreu pelo fato de não terem condições financeiras de morar em outro local, as estratégias mostram suas lutas para obter um espaço. Na sociedade em que se vive, banhado não é local para instalar casas, mas essas mulheres mostram, a partir do governo de si, que não ter condições não as impediu de instalarem-se e viverem no local, escapando da conduta imposta pela sociedade.

Assim, a contraconduta está no ato delas resistirem à situação que encontraram e, além disso, não só resistirem, mas se conduzirem, governarem-se ao ponto de estabeleceremse nesse ambiente, onde algumas delas foram retiradas e voltaram, e outras não saíram de jeito nenhum, mostrando que ali é o espaço que elas deveriam ficar, lutando para obter as políticas públicas necessárias como instalações de água e energia elétrica, criando, inclusive, em suas práticas, um prolongamento na rua Bento Martins. 
Foucault (2008), em sua genealogia da governamentalidade, no curso de 1978, mostra que as contracondutas partiram por insubordinações ao poder pastoral e, conforme Costa (2019, p. 62): "Foucault localiza na genealogia das práticas de governo uma certa condução de condutas". Desse modo, os enfrentamentos narrados pelas mulheres em suas vivências, caracterizados no ato de abrir ruas, usar a estratégia de colocar mangueira na bica, de ir com os irmãos buscar água para otimizar o tempo, demonstram que se conduziram estando numa área de risco de alagamento e poeira, em que o discurso que impera é o que não pode ter moradores naquele espaço, mas, mesmo assim, elas resistiram e ficaram.

Nesse contexto, pode-se utilizar o que Foucault (2008) refere sobre a governamentalidade, que problematiza o governo de si e dos outros, em que as práticas de poder do governo estabelecem regras sobre como a população deve viver em uma sociedade. No caso do grupo social de mulheres inseridas no perímetro urbano de uma cidade, não sendo um local que pode ser chamado de vila, nem de bairro, pois está localizado dentro de um, mas pode ser chamado de um espaço, um pedaço cheio de histórias.

De um modo geral, o Estado não almeja o aumento de periferias e considera-se que, nas cidades, exista um certo controle para que a população não ocupe determinados espaços. Contudo, muitas vezes, as pessoas não têm outro lugar para morar e, sendo assim, acabam aumentando as periferias, fazendo com que esse movimento mostre também a falta de algumas políticas sociais que poderiam amenizar esse quadro. A organização das mulheres sem essas políticas caracteriza a contraconduta ao sistema, através da qual o indivíduo estabelece uma recusa a ser governado no meio social ao qual é subjetivado.

\section{Algumas considerações}

Identificar e analisar a existência de outros jogos de linguagem na forma de vida das mulheres do Quadrado, nos possibilitou compreender outras formas de comparar, medir, associar, classificar, indicar tempo presentes em cada etapa de construção do lugar, além da maneira como o grupo de mulheres conduziu-se frente ao processo de ocupação, valendo-se de movimentos de contraconduta.

Identificaram-se as práticas vivenciadas pelo grupo de mulheres e analisaram-se os jogos de linguagem produzidos em um perspectiva etnomatemática, ao mostrar os usos matemáticos na forma de vida das mulheres, tais como relacionar o tempo ao que existia no início da ocupação, na maneira como aterravam seu espaço, dividiam e demarcavam seu terreno mediante passos, a forma como construíram e numeraram suas casas.

As moradoras mostraram também a existência de outras maneiras de mensurar, realizar associações, indicar o tempo, adaptando as formas e delimitando os espaços e, "só no olho", evidenciam a existência de outras formas de realizar estimativas que atendessem as suas necessidades.

Ao identificar a construção do nome Quadrado a partir das narrativas das mulheres, nota-se que Quadrado é o local de suas moradias atualmente e também serve para indicar o Cais do Quadrado. Com os resultados das análises, percebe-se que os jogos de linguagem produzidos pelas mulheres são a maneira como se expressam, como enxergam o mundo em que vivem decorrentes de suas práticas vivenciadas na forma de vida, as narrativas das mulheres são a produção de seu modo de vida, são suas maneiras de significar o seu mundo, suas práticas e suas histórias.

As mulheres conduzem suas vivências governando a si mesmas, por meio de estratégias próprias de sua forma de vida, como forma de resistência para sobreviver às 
imposições diárias e, mais do que isso, para viver em uma sociedade onde nem todos têm as mesmas oportunidades de condições de moradia decorrentes de um modelo capitalista. Nesse viés, utilizaram um movimento de contraconduta.

À proporção que cada narrativa foi descrita, procedeu-se a um "balanço de um barco num canal" que remete à seleção do que era significativo à pesquisa. Entende-se que a investigação não se esgota aqui, nesse balanço tanto o barco tende para um lado como para outro, mas sabe o seu ponto de partida e de chegada e, chegando no Cais, depara-se com vozes, lembranças, que, por sua vez, foram analisadas, resultando em conhecer um pouco da história do local através das perspectivas relatadas.

Ressignificando tais ditos, foi possível identificar o jogo de linguagem produzido pelo grupo de mulheres em meio a suas práticas vivenciadas "abrir rua", "criar instrumento", "organizar-se". Tais ações vistas sem esse contexto de morar no Quadrado seriam meras atitudes sem objetivos, contudo, suas tarefas tinham objetivos, que eram facilitar suas rotinas, otimizar seu tempo, utilizando recursos disponíveis no momento.

A própria denominação Quadrado se deu mediante a um jogo de linguagem atribuído no uso da comunidade, que, ao se instalar lá e, assim, lutar para permanecer, melhorou suas moradias, aumentando a população da comunidade que sustentou a visibilidade que é dada hoje. As práticas vivenciadas pelo grupo formam alguns saberes que foram construídos em decorrência das suas necessidades para adequar-se no local, em especial em torná-lo um lar.

Neste sentido, justificam-se estudos na perspectiva etnomatemática em locais urbanos, não necessariamente em comunidades rurais, indígenas, quilombolas, com grupos de trabalhadores ou em uma proposta de intervenção escolar. A perspectiva etnomatemática está presente em práticas sociais vistas do passado até o presente, existentes nas falas, nos gestos e nos silêncios, que, através das narrativas das mulheres, permitiu analisar aspectos de práticas de condução de si perante a outros em sua forma de vida.

Entende-se que a investigação não se esgota aqui, existem muitos outros caminhos a percorrer, outros espaços para ocupar. Neste trabalho nos deparamos com vozes, lembranças, que, por sua vez, resultaram em conhecer um pouco da história do Quadrado através das perspectivas relatadas por suas mulheres.

\section{Referências}

AL-ALAM, Tauê Cardoso. De operário a universitário: transformações na paisagem do bairro Porto em Pelotas. 155 f. Dissertação (Mestrado em Geografia) - Universidade Federal de Rio Grande, 2011.

CONDÉ, Mauro Lúcio Leitão. Wittgenstein: Linguagem e mundo. $1^{\text {a }}$ edição. São Paulo: Annablume, 1998.

COSTA, Helrison Silva. O lugar das Contracondutas na Genealogia Foucaultiana do Governo. Revista de Filosofia Moderna e Contemporânea, Brasília, v.7, n 1, p. 61-78, abr. 2019.

FISCHER, Rosa Maria Bueno. Foucault e a Análise do discurso em Educação. Cadernos de Pesquisa, São Paulo, n.114, p.197-223, nov.2001.

FOUCAULT, Michel. Segurança, Território, População: curso dado no Collège de France (1977-1978). Trad. Eduardo Brandão. São Paulo: Martins Fontes, 2008.

A arqueologia do saber. 7a edição. Rio de janeiro: Forense Universitária, 2008a. 
IBRAHIM, Elza; VILHENA, Junia. Jogos de linguagem/jogos de verdade: de Wittgenstein a Foucault. Arquivos Brasileiros de Psicologia, Rio de Janeiro, v. 66, n. 2, p. 114-127, 2014.

KNIJNIK, Gelsa. A ordem do discurso da matemática escolar e jogos de linguagem de outras formas de vida. Perspectivas da Educação Matemática, Cuiabá, v. 10, n. 22, p. 45-64, jan./maio 2017.

KNIJNIK, Gelsa. et al. Etnomatemática em movimento. 2a edição. Belo Horizonte: Autêntica, 2013 (Coleção Tendências em Educação Matemática, 25).

KNIJNIK, Gelsa. Itinerários da Etnomatemática: questões e desafios sobre o cultural, o social e o político na educação matemática. In: KNIJNIK, G.; WANDERER, F.; OLIVEIRA, C. J. de (Orgs.).

Etnomatemática, currículo e formação de professores. Santa Cruz do Sul: EDUNISC, 2010.

MEYER, Dagmar; PARAÍSO, Marlucy Alves. Metodologias pós-críticas ou sobre como fazemos nossas investigações. In: MEYER, Dagmar; PARAÍSO, Marlucy Alves. Metodologias de pesquisas pós-críticas em educação. Belo Horizonte: Mazza Edições, 2012.

MORENO, Arley Ramos. Wittgenstein: através das imagens. $2^{\mathrm{a}}$ edição. Campinas, SP: editora da UNICAMP, 1995 (coleção repertórios).

PARAÍSO, Marlucy Alves. Metodologias de pesquisas pós-críticas em educação e currículo: trajetórias, pressupostos, procedimentos e estratégias analíticas. In: MEYER, Dagmar; PARAÍSO, Marlucy Alves. Metodologias de pesquisas pós-críticas em educação. Belo Horizonte: Mazza Edições, 2012.

RAGO, Margareth. Foucault para uma vida não fascista. Seminário Contracondutas, São Paulo, 2016. Disponível em: http://www.ctescoladacidade.org/contracondutas/seminarios/seminario-primeirociclo/margareth-rago/. Acesso em: 10 dez. 2019.

VEIGA-NETO, Alfredo; LOPES, Maura Corcini. Gubernamentalidad, biopolítica y inclusión. In: CORTÉSSALCEDO, R.; MARÍN-DÍAZ, D.(comp.). Gubernamentalidad y educacíon: discusiones contemporâneas. Bogotá: IDEP, p.105-122, 2011.

VEIGA-NETO, Alfredo; LOPES, Maura Corcini. Inclusão como dominação do outro pelo mesmo. In: VII Colóquio Internacional Michel Foucault. out. 2011.São Paulo: PUC-SP, 2011a.

WITTGESTEIN, Ludwig. Investigações filosóficas. Trad. José Carlos Bruni, São Paulo: Nova Cultural Ltda, 2000. (Coleção Os Pensadores).

\section{Agradecimento}

O presente trabalho foi realizado com apoio da Universidade Federal de Pelotas (UFPel) - Programa PIB-M/D. 